\title{
Dying comfortably in very old age with or without dementia in different care settings - a representative "older old" population study
}

Jane Fleming ${ }^{1,2^{*}}$ D, Rowan Calloway ${ }^{1,3}$, Anouk Perrels ${ }^{1,4}$, Morag Farquhar ${ }^{5}$, Stephen Barclay ${ }^{1,2,6}$, Carol Brayne Fi,2 $^{1,2}$ on behalf of the Cambridge City over-75s Cohort (CC75C) study ${ }^{1}$

\begin{abstract}
Background: Comfort is frequently ranked important for a good death. Although rising numbers of people are dying in very old age, many with dementia, little is known about symptom control for "older old" people or whether care in different settings enables them to die comfortably. This study aims to examine, in a population-representative sample, associations between factors potentially related to reported comfort during very old people's final illness: physical and cognitive disability, place of care and transitions in their final illness, and place of death.
\end{abstract}

Methods: Retrospective analyses linked three data sources for $n=180$ deceased study participants (68\% women) aged 79-107 in a representative population-based UK study, the Cambridge City over-75s Cohort (CC75C):

i) prospective in-vivo dementia diagnoses and cognitive assessments,

ii) certified place of death records,

iii) data from interviews with relatives/close carers including symptoms and "How comfortable was he/she in his/her final illness?"

Results: In the last year of life 83\% were disabled in basic activities, 37\% had moderate/severe dementia and 45\% minimal/mild dementia or cognitive impairment. Regardless of dementia/cognitive status, three-quarters died following a final illness lasting a week or longer. 37\%, 44\%, 13\% and 7\% of the deceased were described as having been "very comfortable", "comfortable", "fairly comfortable" or "uncomfortable" respectively during their final illness, but reported symptoms were common: distress, pain, depression and delirium or confusion each affected 40-50\%. For only $10 \%$ were no symptoms reported. There were $\geq 4$-fold increased odds of dying comfortably associated with being in a care home during the final illness, dying in a care home, and with staying in place (dying at what death certificates record as "usual address"), whether home or care home, compared with hospital, but no significant association with disability or dementia/cognitive status, regardless of adjustment.

(Continued on next page)

\footnotetext{
* Correspondence: jane.fleming@phpc.cam.ac.uk

${ }^{1}$ Cambridge Institute of Public Health, University of Cambridge, Forvie Site,

Robinson Way, Cambridge CB2 OSR, UK

${ }^{2}$ Department of Public Health \& Primary Cambridge, University of Cambridge,

Cambridge, UK

Full list of author information is available at the end of the article
} 
(Continued from previous page)

Conclusions: These findings are consistent with reports that care homes can provide care akin to hospice for the very old and support an approach of supporting residents to stay in their care home or own home if possible. Findings on reported high prevalence of multiple symptoms can inform policy and training to improve older old people's end-of-life care in all settings.

Keywords: 'Older old' / 'oldest old' / 'old old' / 'old* old', 'End of life care' / 'end-of-life care', 'Place of care' / 'place of death', Comfort, 'Symptom control', Aged, 80 and over, Frail elderly, Palliative care, Terminal care, Symptoms, Homes for the aged, Nursing homes

\section{Background}

Increasing longevity means more people are dying at increasingly older ages, often with multiple comorbidities complicating their end-of-life care $[1,2]$. In the UK, for example, over just the last quarter century the proportion of deaths occurring at the age of 85 or older has risen steeply from around a fifth in 1990 to almost half current annual deaths [3]. Dementia prevalence rises with proximity to death, over and above age-associated increases [4]. Multiple symptoms are common amongst older people with dementia as they approach the end of life and poor symptom control may increase distress and worsen quality of life [5]. Past research in both hospital and long-term care settings has highlighted concerns that failure to recognise dementia as a terminal condition and communication breakdown may both contribute to poor symptom management $[5,6]$. Variation in levels of symptom control for all older people dying in different care settings, with or without dementia, is an important concern. [7, 8] Comfort and effective symptom management feature high in patients' [9-13], relatives' [14, 15] and professionals' [16] perceptions concerning what factors are important for a good death. In a study of advance care planning amongst older adults $92 \%$ of patients prioritised comfort [17].

Most people taking part in surveys about their future wishes [18-20] or reporting what they believe their relatives wanted $[7,21]$ state a preference to die at home, if expressed at all. These widely quoted findings may not be representative [22], nor reflect how views can vary with proximity to death $[20,23$, $24]$ and personal circumstances [25, 26]. Although policy encourages support for patients to die wherever they would prefer $[27,28]$, dying at home is a more measurable outcome than death in preferred place of care so is often taken as a surrogate indicator of end-of-life care supporting choice [29, 30]. However, a minority of the oldest old people die in their own homes [8, 31-33] and indeed research shows that many older people anticipate preferring to be cared for elsewhere in the final illness $[18,19,25,26,34]$.
In the UK fewer older people die in hospices or receive specialist palliative care at home than younger age-groups [35-38] and the trend for older deaths is gradually moving away from death in hospital towards long-term care facilities $[39,40]$.

For older people in many countries care transitions are common during the last weeks [41], months [42, 43] or year [31] of life. Those with cognitive impairment are most likely to live in and subsequently die in care homes $[44,45]$, while those with no or mild cognitive impairment are more likely to live at home in the community and then be admitted into acute facilities during the terminal phase [32]. As well as cognitive status, other factors have been reported to influence transitions such as gender, affluence of area and diagnosis [39, 46, 47]. In studies that analysed causes of transitions a common theme was that uncertain diagnosis, less skilled members of staff, communication difficulties and needing to access out of hours services made hospital admission more likely [43, 48-50].

Transitions towards the end of life can be burdensome and may not be associated with symptom improvement nor with better quality end-of-life care. They may result in exclusion of the main carer and a disjointed experience of the health service [51], even leading to adverse events in drug prescription [52]. Admission to hospital at the end of life is also associated with greater cost [53-55]: UK health service spending exceeding $£ 750 \mathrm{~m}$ a year on emergency admissions ending in death [27], and evidence suggests hospitalisation for patients with severe dementia is not cost effective [56].

There are several gaps in the literature concerning comfort at the end of life amongst older old people. Although there is extensive research concerning their preferred place of care, few studies have compared endof-life care across different settings and there is little evidence to support the commonly-held view that transitions have a negative effect on quality of end-of-life care. Few studies have been able to link individual-level data including dementia or cognitive status prospectively assessed before death with information on where and how dying individuals were cared for. This study has achieved this, examining in a population-representative 
sample the associations between factors potentially related to reported comfort during the final illness of very old people - in particular, their cognitive and physical disability, the setting where they were cared for in their final illness, and where they died.

\section{Methods}

Analyses of data from a prospective population-based study of ageing in which almost all respondents have died, the Cambridge City over-75s Cohort (CC75C) study [57], linked i) in vivo dementia diagnoses and cognitive assessments with ii) certified place of death records and iii) data from interviews with bereaved relatives or other closely involved carers ("informants") for the maximum subsample with all three data sources $(n=180)$. The CC75C study [58] has followed up 2166 men and women aged at least 75 at baseline (1985-87) enrolled through general practices (95\% response rate) in Cambridge, UK, with surveys every few years until death (all deceased by December 2015). The study remained highly representative of the older old population, with mortality the main reason for attrition.

\section{Cognitive assessment}

Each survey wave has included a detailed cognitive assessment, including the Mini Mental State Examination (MMSE) [59]. Almost half the cohort $(n=1022)$ had further in-depth investigation at least once following Surveys 1-3: the Cambridge Mental Disorders of the Elderly Examination (CAMDEX) [60], a psychiatristadministered interview schedule for the diagnosis of dementia.

After death, a consensus diagnosis of dementia status at death consistent with the Diagnostic and Statistical Manual of Mental Disorders version 4 (DSM-IV) [61] criteria was made by two clinicians experienced in old age psychiatry. This diagnosis was based on review of all available information including survey data, proxy informant data, general practitioner (GP) confirmation of dementia diagnosis, death certificates and data from retrospective informant interviews after participants had died [62].

\section{Definition of dementia status}

"Dementia status" was categorized in three categories: "no cognitive impairment - no dementia", "cognitive impairment - minimal/mild dementia" and "moderate/severe dementia". Participants who had undergone CAMDEX assessments less than a year before death or clinical diagnosis at death were assigned to these categories according to dementia severity ratings. Those whose death certificate recorded dementia were assumed to have moderate/severe dementia. Participants who had no confirmed dementia status were categorized on the basis of severity of cognitive impairment as measured by MMSE less than two years before death: no dementia - no cognitive impairment (26-30), cognitive impairment - minimal/mild dementia (18-25) and moderate/severe dementia (0-17).

\section{Reported symptoms and comfort}

For participants who joined the study's brain donor programme, or another sub-study, a retrospective interview after their death with a close relative or carer collected information on the period between the participant's last interview and death $(n=290)$. Funding limitations meant only informants for these participants were approached ( $81 \%$ response rate) and for a minority approaches to request interview were missed but followed-up later $(n=10$ more than ten years after the participant died). This included the CAMDEX informant interview schedule and questions about the participant's care at the end of their life [63]. Questions included "Overall, how comfortable was s/he during the final illness?" (very/fairly comfortable, somewhat/very uncomfortable), "Did s/he suffer any of the following symptoms during his/her final illness?" (see Results for symptom list) and "If YES to any of these, was treatment given for this problem and how effective was it?" (free text responses categorised "Yes", "Somewhat", "No" or "Unknown"). Informants were asked for their estimate of duration of what they considered the "final illness" ( $\leq 1$ week, 1 week to 1 month, $>1$ month).

\section{Analyses}

The analysed sample $(n=180)$ was all participants with retrospective informant interviews providing data on comfort in their final illness, excluding participants of unknown dementia status whose last cognitive assessment was two or more years before they died. Descriptive analyses summarised participant and informant characteristics, the prevalence of reported symptoms, treatment and effectiveness for these symptoms, and reported comfort in the final illness. Logistic regression examined the relationship between being described as comfortable (four responses dichotomised comfortable/ uncomfortable) in the final illness and each potentially related factor. Factors identified as significantly associated with comfort in univariate analyses $(p<0.05)$ and dementia status, which was hypothesised a priori to be a relevant factor, were separately entered in regression analyses adjusting for each of these factors individually. The extent of correlations between factors found to be significant in univariate regression, and between these and dementia status, were explored using descriptive bivariate crosstabulations. Sample size, the number of factors of interest and their strong inter-dependence meant multiple regression was inappropriate. All statistical and descriptive analyses were performed using the statistical package 
STATA Version 12 (Stata Corporations, College Station, TX).

\section{Patient involvement}

When the CC75C study began in the mid-1980s there was no patient involvement. Participants and their relatives have been included in dissemination of the cohort study's findings through annual newsletters until the last participant died in 2015. The broad public involvement in the James Lind Alliance Palliative and End of Life Care Priority Setting Partnership [64] helped inform research questions for the study here reported.

\section{Ethical approval}

Each stage of the CC75C study has been approved by the local Research Ethics Committee.

\section{Results}

\section{Characteristics of the study participants}

The sample for this analysis was all 180 cohort participants (57 men, 123 women) for whom dementia status was defined and informant data were available reporting symptoms and how comfortable they were in their final illness (see Fig. 1). Table 1 shows the deceased study participants' characteristics, overall and by dementia status.

Over a third of individuals (37\%) were assessed as having "moderate/severe dementia", $45 \%$ as having "cognitive impairment - minimal/mild dementia" and $18 \%$ as having "no dementia - no cognitive impairment" when last interviewed. The age at time of death across all groups ranged from 79 to 107 years, (median [IQR] 91.3 [87.5-94.4]). Participants without dementia or cognitive impairment were younger at death than those with moderate/severe dementia (median [IQR] 89.7 [87.1-92.0], 92.3 [88.5-95.7] respectively). There were more women than men $(68 \%, 32 \%$ respectively), especially amongst the individuals with any severity of dementia and/or cognitive impairment, and two-thirds had been widowed (68\%). Demographics and distributions of cognition and dementia status in the analysis sample reflected those in the full cohort.

Participants with 'no cognitive impairment - no dementia' or with "cognitive impairment - minimal/mild dementia" were mainly living at home when last interviewed (94\%, 90\% respectively), compared with only $45 \%$ those with moderate/severe dementia. The majority of community-dwelling participants at home lived alone $(61 \%)$ and received service support at least once a week when last interviewed (66\%). Nearly all the participants had disabilities in both instrumental and basic activities in daily living (83\%), ranging from $64 \%$ to $97 \%$ across categories of increasing dementia severity. For about three-quarters of the participants the duration of their final illness was reported to be longer than six days, regardless of dementia status.

There were marked differences in the older adults' place of care during their final illness and their place of death depending on their dementia status. Although fewer than half the participants had been admitted to a hospital since they were last interviewed, hospital was the most common place of end-of-life care and death for individuals in the unimpaired or intermediate groups. For those with "moderate/severe dementia" long-term care was the most likely setting for both end-of-life care (76\%) and death (76\%), although about one in six had

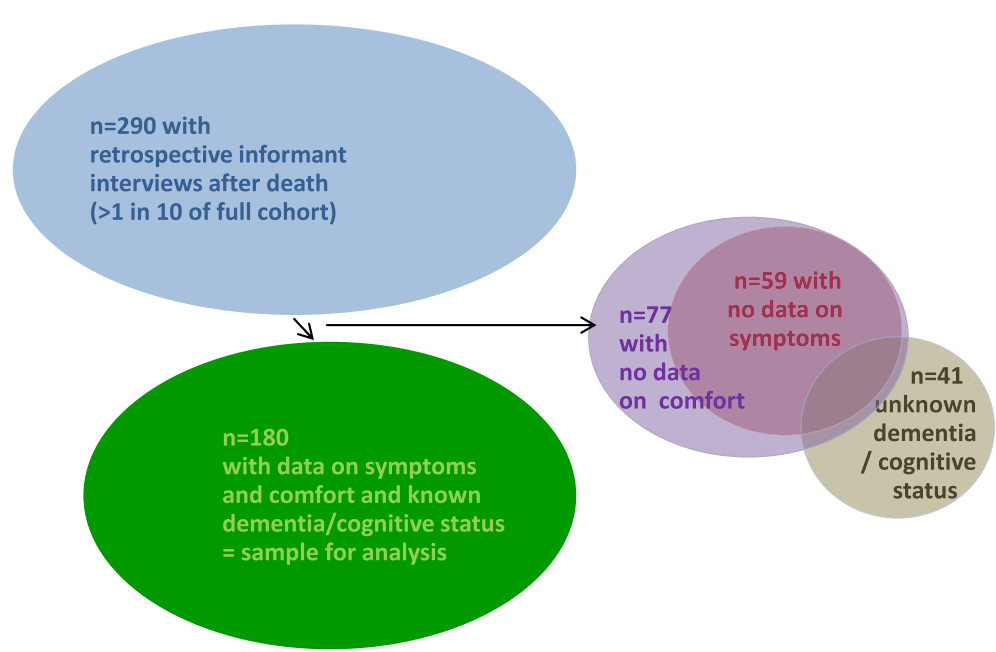

Fig. 1 Identification of participants with retrospective informant interviews for analysis sample. This study, nested in a representative population-based cohort, analysed data from the branch study in which for approximately one in ten of the full cohort, by design, proxy informant interviews were conducted after participants died. Participants were excluded if their dementia / cognitive status by the time they died was unknown or if retrospective informant interview questions on their level of comfort and symptoms experienced during their final illness had missing data 
Table 1 Characteristics of deceased study participants

\begin{tabular}{|c|c|c|c|c|c|c|c|c|}
\hline & \multicolumn{2}{|c|}{$\begin{array}{l}\text { No dementia, no } \\
\text { cognitive impairment } \\
n=33\end{array}$} & \multicolumn{2}{|c|}{$\begin{array}{l}\text { Minimal-mild dementia, } \\
\text { moderate cognitive impairment } \\
n=81\end{array}$} & \multicolumn{2}{|c|}{$\begin{array}{l}\text { Moderate-severe dementia, } \\
\text { severe cognitive impairment } \\
n=66\end{array}$} & \multicolumn{2}{|c|}{$\begin{array}{l}\text { Total } \\
n=180\end{array}$} \\
\hline & $\mathrm{n}$ & (\%) & $n$ & $(\%)$ & $\mathrm{n}$ & $(\%)$ & $\mathrm{n}$ & (\%) \\
\hline \multicolumn{9}{|l|}{ Age at death } \\
\hline Median [IQR] & 89.7 & {$[87.1-92.0]$} & 90.7 & [86.9-94.2] & 92.3 & {$[88.5-95.7]$} & 91.3 & {$[87.5-94.4]$} \\
\hline [range] & & {$[81.6-102.8]$} & & [79.2-106.7] & & [89.9-100.8] & & [79.2-106.7] \\
\hline$\leq 89$ years old & 19 & (58) & 36 & (44) & 23 & (35) & 78 & (43) \\
\hline$\geq 90$ years old & 14 & $(42)$ & 45 & (56) & 43 & $(65)$ & 102 & (57) \\
\hline \multicolumn{9}{|l|}{ Sex } \\
\hline Male & 16 & $(48)$ & 27 & (33) & 14 & $(21)$ & 57 & (32) \\
\hline Female & 17 & $(52)$ & 54 & (67) & 52 & (79) & 123 & (68) \\
\hline \multicolumn{9}{|l|}{ Marital status } \\
\hline Married & 5 & (15) & 16 & (20) & 17 & $(26)$ & 38 & (21) \\
\hline Widowed & 27 & $(82)$ & 54 & (67) & 42 & $(64)$ & 123 & (68) \\
\hline Separated/Divorced & 1 & (3) & 0 & (0) & 1 & $(2)$ & 2 & (1) \\
\hline Single & 0 & $(0)$ & 11 & (14) & 6 & (9) & 17 & (9) \\
\hline \multicolumn{9}{|l|}{ Education } \\
\hline Left school aged $\leq 14$ & 17 & $(52)$ & 56 & (69) & 42 & $(64)$ & 115 & (64) \\
\hline Left school aged $\geq 15$ & 16 & $(48)$ & 25 & (31) & 23 & $(35)$ & 64 & (36) \\
\hline School leaving age unknown & 0 & $(0)$ & 0 & (0) & 1 & $(2)$ & 1 & $(<1)$ \\
\hline \multicolumn{9}{|l|}{ Social class ${ }^{a}$} \\
\hline Non-manual & 17 & $(52)$ & 30 & (37) & 32 & $(48)$ & 79 & (44) \\
\hline Manual & 16 & $(48)$ & 51 & (63) & 32 & $(48)$ & 99 & (55) \\
\hline Social class unknown & 0 & $(0)$ & 0 & (0) & 2 & (3) & 2 & (1) \\
\hline \multicolumn{9}{|l|}{ Place of residence last interview ${ }^{b}$} \\
\hline Home (house, flat or 'granny flat') & 31 & $(94)$ & 73 & (90) & 30 & $(45)$ & 134 & (74) \\
\hline alone & 20 & $(65)$ & 48 & (66) & 14 & $(47)$ & 82 & (61) \\
\hline with others & 11 & (35) & 25 & (34) & 16 & (53) & 52 & (39) \\
\hline Long-term care ${ }^{a}$ & 2 & (6) & 8 & (10) & 36 & (55) & 46 & (26) \\
\hline residential care home & 2 & $(100)$ & 7 & (88) & 33 & $(92)$ & 42 & (92) \\
\hline nursing home & 0 & $(0)$ & 0 & (0) & 2 & (6) & 2 & (4) \\
\hline long-stay ward & 0 & $(0)$ & 1 & (13) & 1 & (3) & 2 & (4) \\
\hline
\end{tabular}

Disability in activities of daily living when last interviewed

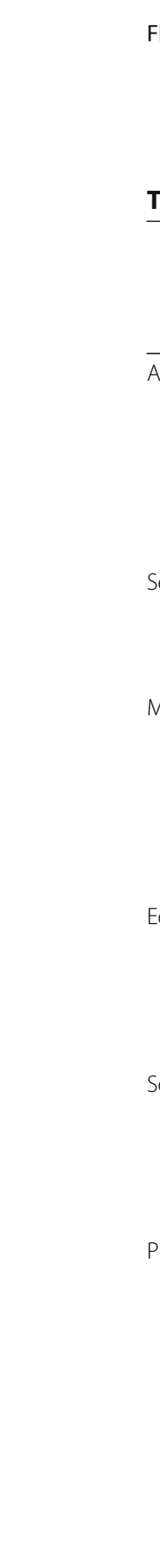

at death

$\leq 89$ years old

[81.6-102.8]

[79.2-106.7]

[89.9-100.8]

[79.2-106.7]

Male

ital status

Widowed

separated/Divorced

cation

eft school aged $\leq 14$

(21)

Disability: instrumental ADLs only 5

2

(2)

(2)

(6)

Disability: basic + instrumental ADLs 21

(64)

(17)

(80)

(2)

(97)

65

64

(29)

(29)

(33)

(33)

(27)

(40)

(7)

(0) 2

(3)

Hospital admissions between last interview and death

$\begin{array}{llll}\text { None } & 17 & (52) & 42 \\ \text { One or more } & 15 & (45) & 35 \\ \text { Unknown } & 1 & (3) & 4\end{array}$

$42 \quad(52)$

(52)

(43)

(5)

(3) 7 
Table 1 Characteristics of deceased study participants (Continued)

\begin{tabular}{|c|c|c|c|c|c|c|c|c|}
\hline & \multicolumn{2}{|c|}{$\begin{array}{l}\text { No dementia, no } \\
\text { cognitive impairment } \\
n=33\end{array}$} & \multicolumn{2}{|c|}{$\begin{array}{l}\text { Minimal-mild dementia, } \\
\text { moderate cognitive impairment } \\
n=81\end{array}$} & \multicolumn{2}{|c|}{$\begin{array}{l}\text { Moderate-severe dementia, } \\
\text { severe cognitive impairment } \\
n=66\end{array}$} & \multicolumn{2}{|c|}{$\begin{array}{l}\text { Total } \\
n=180\end{array}$} \\
\hline & $n$ & $(\%)$ & $n$ & (\%) & $\mathrm{n}$ & (\%) & $\mathrm{n}$ & (\%) \\
\hline \multicolumn{9}{|c|}{ Hospital admissions per year between last interview and death, if any } \\
\hline Median $[\mathrm{IQR}]$ & 0.9 & {$[0.6-1.7]$} & 0.7 & {$[0.5-1.7]$} & 0.6 & {$[0.4-1.2]$} & 0.8 & {$[0.5-1.6]$} \\
\hline [range] & & {$[(0.2-29.6]$} & & {$[0.2-3.7]$} & & {$[0.2-4.6]$} & & {$[0.2-29.6]$} \\
\hline \multicolumn{9}{|l|}{ Duration of final illness } \\
\hline Less than 1 week & 8 & $(24)$ & 19 & $(23)$ & 17 & (26) & 44 & (24) \\
\hline 7 days up to 1 month & 16 & $(49)$ & 36 & $(44)$ & 28 & $(42)$ & 80 & $(44)$ \\
\hline 1 month or more & 9 & $(27)$ & 26 & $(32)$ & 21 & (32) & 56 & $(32)$ \\
\hline \multicolumn{9}{|c|}{ Place of care during final illness ${ }^{b}$} \\
\hline Home & 11 & (33) & 17 & $(21)$ & 5 & (8) & 33 & (18) \\
\hline Long-term care & 4 & $(12)$ & 18 & (22) & 50 & (76) & 72 & $(40)$ \\
\hline Hospital & 18 & $(55)$ & 46 & $(57)$ & 11 & (17) & 75 & $(42)$ \\
\hline \multicolumn{9}{|l|}{ Place of death ${ }^{b}$} \\
\hline Home & 4 & $(12)$ & 12 & $(15)$ & 3 & (5) & 19 & (11) \\
\hline Long-term care & 7 & $(21)$ & 19 & $(23)$ & 50 & (76) & 76 & $(42)$ \\
\hline Hospital & 22 & $(67)$ & 50 & $(62)$ & 13 & (20) & 85 & $(47)$ \\
\hline \multicolumn{9}{|c|}{ Place of death not usual address } \\
\hline No & 7 & $(21)$ & 25 & $(31)$ & 43 & (65) & 75 & $(42)$ \\
\hline Yes & 26 & $(79)$ & 56 & $(69)$ & 23 & (35) & 105 & (58) \\
\hline \multicolumn{9}{|c|}{ Time from last interview to death } \\
\hline Years: median [IQR] & 1.8 & {$[1.2-2.5]$} & 1.6 & {$[0.8-2.5]$} & 2.2 & {$[1.0-3.3]$} & 1.8 & {$[1.0-2.8]$} \\
\hline [range] & & {$[0.1-5.3]$} & & {$[0.3-5.7]$} & & {$[0.1-6.8]$} & & {$[0.1-6.8]$} \\
\hline
\end{tabular}

Footnotes

Column percentages total $100 \%$ - apparent slight discrepancies due to rounding

${ }^{a}$ Social class categorised following contemporary UK Office of National Statistics grading of occupation reported at baseline interview:

Non-manual = I, II or IIla, Manual = IIlb, IV or V

bome: community-dwelling in a house, flat, 'granny flat' (part of a relative's home) or sheltered accommodation

Long-term care: in an older people's residential home, nursing home or long-stay ward

Hospital: in an acute hospital

Characteristics of the deceased, shown separately for study participants of different cognitive status and overall, summarise data drawn from interviews with the participants before they died and proxy informants after the participant died, CC75C study administrative data and death certificates

received hospital care during their final illness and a fifth had died in hospital. Very few of this group had received community end-of-life care or died at home ( $8 \%$ and $5 \%$ respectively).

Overall, the majority had experienced a change in residence or care in the period prior to death (the "usual address" recorded on their death certificate differed from their place of death), though this was far less common for people with moderate/severe dementia (35\%) than for the cognitively unimpaired (79\%).

The median time from the last study interview until a participant's death was 1.8 years (IQR $1-2.8$ ), with a slightly longer duration amongst participants with "moderate/severe dementia".

The analysis sample broadly reflected the full representative cohort's demographics, with very similar distributions by sex, education level and social class, but they were just over a year older at death (91.1 versus 89.9 years), more likely to be widowed (68\% versus $56 \%$ ) and more likely living in care (26\% versus $16 \%)$. Disability levels were higher in our sample but the distribution of known dementia status and cognition were similar.

\section{Characteristics of the retrospective interview informants} Most informants were relatives of the participants (86\%, of whom nearly two-thirds were sons or daughters) and $68 \%$ were women (see Table 2). Most had been in regular contact with the participants, seeing them more than once a week $(84 \%)$. For $17 \%$ of participants who died in long-term care the only available informant was a member of staff in the care home. The median time 
Table 2 Characteristics of informants

\begin{tabular}{|c|c|c|}
\hline & \multicolumn{2}{|c|}{ Total $n=180$} \\
\hline & $\bar{n}$ & (\%) \\
\hline \multicolumn{3}{|l|}{ Sex } \\
\hline Female & 123 & $(68)$ \\
\hline Male & 57 & $(32)$ \\
\hline \multicolumn{3}{|l|}{ Relationship to deceased } \\
\hline Husband or wife & 18 & $(10)$ \\
\hline Son or daughter & 97 & $(54)$ \\
\hline Other relative & 40 & $(22)$ \\
\hline Friend & 8 & (4) \\
\hline Matron or warden ${ }^{\mathrm{a}}$ & 15 & (8) \\
\hline Unknown & 2 & $(1)$ \\
\hline \multicolumn{3}{|c|}{ Frequency of contact with deceased study participant before they died } \\
\hline Lived with her/him & 29 & $(16)$ \\
\hline Daily & 45 & $(25)$ \\
\hline At least once a week & 77 & $(43)$ \\
\hline Less than once a week & 29 & $(16)$ \\
\hline \multicolumn{3}{|c|}{$\begin{array}{l}\text { Interval from study participant's death to retrospective informant } \\
\text { interview }\end{array}$} \\
\hline Years: median [IQR] & 2.3 & {$[1.3-3.7]$} \\
\hline \multicolumn{3}{|c|}{$\begin{array}{l}\text { Footnotes } \\
\text { Column percentages total } 100 \% \text { for each sub-group - apparent slight } \\
\text { discrepancies due to rounding } \\
\text { aMatron or other member of staff in a care home, or warden in a sheltered } \\
\text { housing scheme } \\
\text { Most informants were women, usually relatives, most often a daughter or } \\
\text { son, and the majority had been in close contact with the deceased } \\
\text { participant before they died: } \mathbf{8 4 \%} \text { were either living with them, visiting } \\
\text { daily or seeing them more than once a week }\end{array}$} \\
\hline
\end{tabular}

between the participant's death and the informant interview was 2.3 years (IQR 1.3-3.7 years; range 1 month to 14.1 years).

\section{Reported symptoms in the final illness}

Informants were asked whether the study participant suffered any of a list of seven symptoms in their final illness. The distribution of symptoms reported (Fig. 2a) varied for older people of different cognitive status (Fig. 2b); both figures show firm reports and cases when informants were unsure whether or not a symptom was experienced (responses "Yes" and "Don't know"). Apart from expected high rates of "delirium and confusion" amongst those with moderate/severe dementia, pain and distress were the most commonly reported symptoms. Informants were most unsure whether or not the participant had suffered from depression. For only $n=$ $18(10 \%)$ were none of these symptoms reported, and for a further $n=7$ (4\%) informants were unsure whether the participant had suffered any of these symptoms. A quarter were reported to have experienced just one symptom, but the majority (61\%) reportedly suffered at least two symptoms and $42 \%$ three or more. Figure 3 illustrates for the full sample the complex overlap of symptoms, showing only symptoms reported as "Yes".

Figure 4 illustrates what percentage of the people who were reported to have had pain $(n=73,41 \%)$, depression $(n=51,29 \%)$ and pressure sores $(n=29,16 \%)$ were also reported to have had treatment for these and, of these treated, for what percentage treatment was reported to have been effective. For example, of the $41 \%$ reported to have had pain $78 \%$ reportedly had pain-relieving treatment, for whom informants reported 53\% found this effective, i.e. only $41 \%$ of those in pain were thought to have had adequate pain relief (53\% of $78 \%$ ). Informants were frequently uncertain as to whether these symptoms were experienced, treated and, if so, whether symptoms were relieved. This was particularly so for depression and pressure sores.

\section{Reported comfort in the final illness}

"How comfortable was s/he in his/her final illness" was answered positively by the majority of informants: $37 \%$ described the deceased older person as having been "very comfortable", 44\% "comfortable", $13 \%$ "somewhat uncomfortable" and 7\% "very uncomfortable". These high proportions reported as comfortable included many with symptoms as described above, with informants reporting effective treatment more often for those rated comfortable than for those rated uncomfortable (60\% versus $44 \%$, non-significant difference, $p=0.2$, in the small subsample reported to have received symptom treatment: $n=67)$. Informants for individuals in the more severe cognitive impairment group were more likely uncertain whether any treatment given was effective than for the cognitively intact $(25 \%$ and $8 \%$ respectively, $p=0.6$ ) and less likely to report treatment as effective (52\% and $75 \%$ respectively, $p=0.3)$. Nonetheless, the most cognitively impaired individuals were most likely to be rated comfortable (respectively $76 \%, 75 \%$ and $89 \%$ of each dementia status category, $p=0.07)$, a finding consistent with the high prevalence of reported comfort for those whose endof-life care was in long-term care (see Table 3).

Table 3 shows the distribution of reported comfort in the final illness across categories of each descriptive characteristic and gives the unadjusted odds ratio (OR) for reportedly having been comfortable associated with each factor. Compared with care or death in hospital, there was at least a 4-fold increased odds of dying comfortably associated with being in a care home during the final illness, with dying in a care home, with staying in place in a care home (i.e. when a care home was the location for both end-of-life care and death) and dying at the participant's "usual address" (home or 


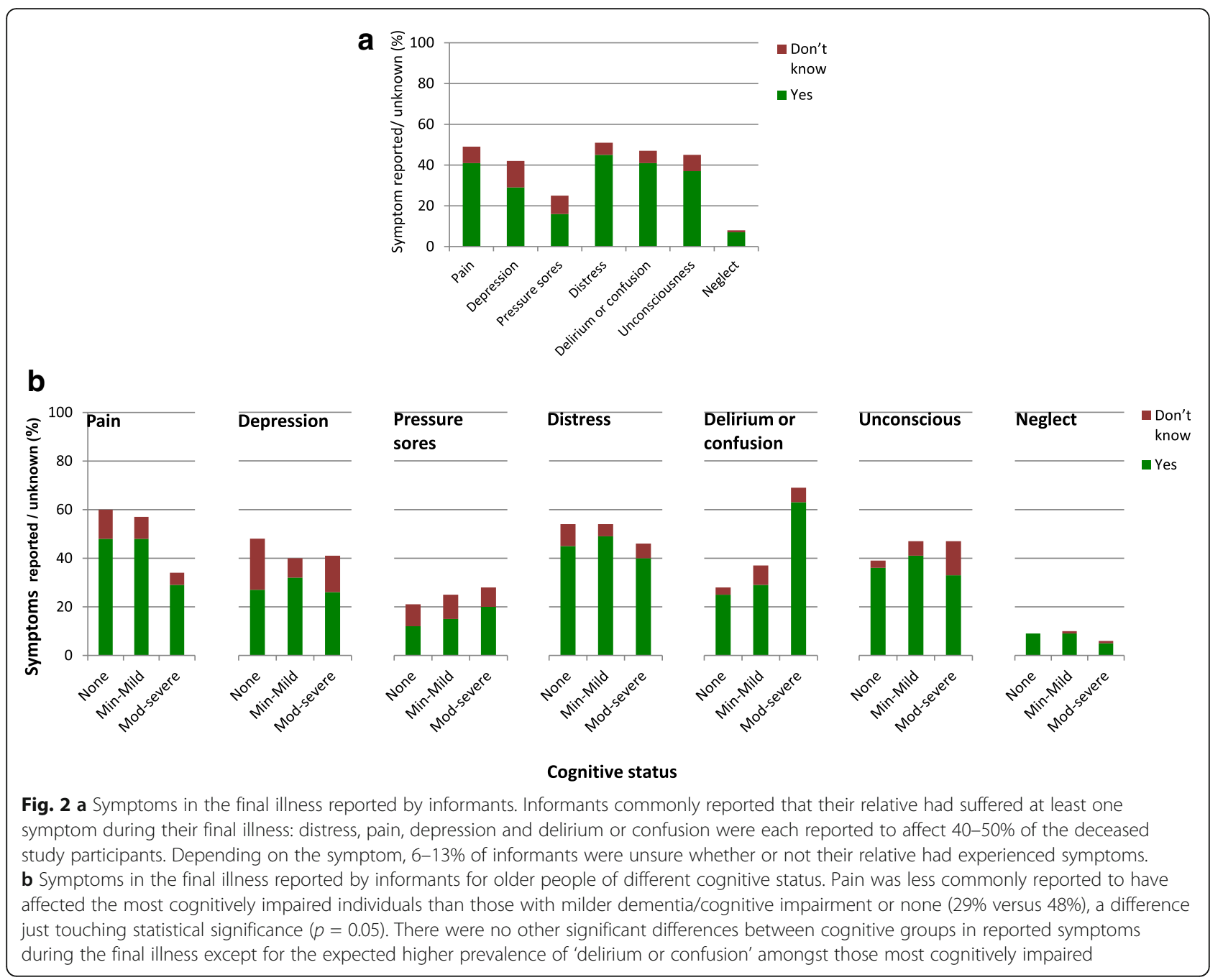

care home). Although people who died at home or in long-term care were similarly commonly reported comfortable (89\% and 91\%, versus 69\% for hospital deaths), there were too few deaths at home for the association between dying at home and comfort to reach significance: OR 3.7 (95\% CI 0.8-17.4). People with home or hospital care in the final illness were equally commonly reported comfortable (both 73\%, versus 92\% in long-term care). However, compared with those who were cared for in hospital until death, the odds of dying comfortably were just significantly lower for those who died in hospital after having been cared for at home: OR 0.29 (95\% CI 0.09-0.98). Those who were living at home when last surveyed, needing no support from formal services or needing support only once a week, had a 3 -fold increased odds of a comfortable death compared with those needing support twice a week or more.

Adjusting for the covariates found significant in univariate analyses had minimal impact on most associations with reported comfort, but reduced effect sizes and significance for some most closely inter-related factors, though not all (see Additional file 1: Table S1). For example, taking into account 'death at usual address' reduced the effect of end-of-life care location factors, but adjusting for the level of service support needed in the community-dwelling sub-sample strengthened the association with comfort of dying in long-term care. The nonsignificant association between dementia status and dying comfortably was slightly reduced by adjusting for any significant factor. Adjusting for the time interval between participant deaths and informant interviews also made minimal or no difference to associations with other factors (see Additional file 2: Table S2).

Figure 5 illustrates how closely inter-related the place of care factors are: the majority of people who died in a care home had also been cared for in their final illness in a care home. This was usually the same home. Likewise, when care during the final illness was in hospital, this was usually the place of death too. However, more than half the 


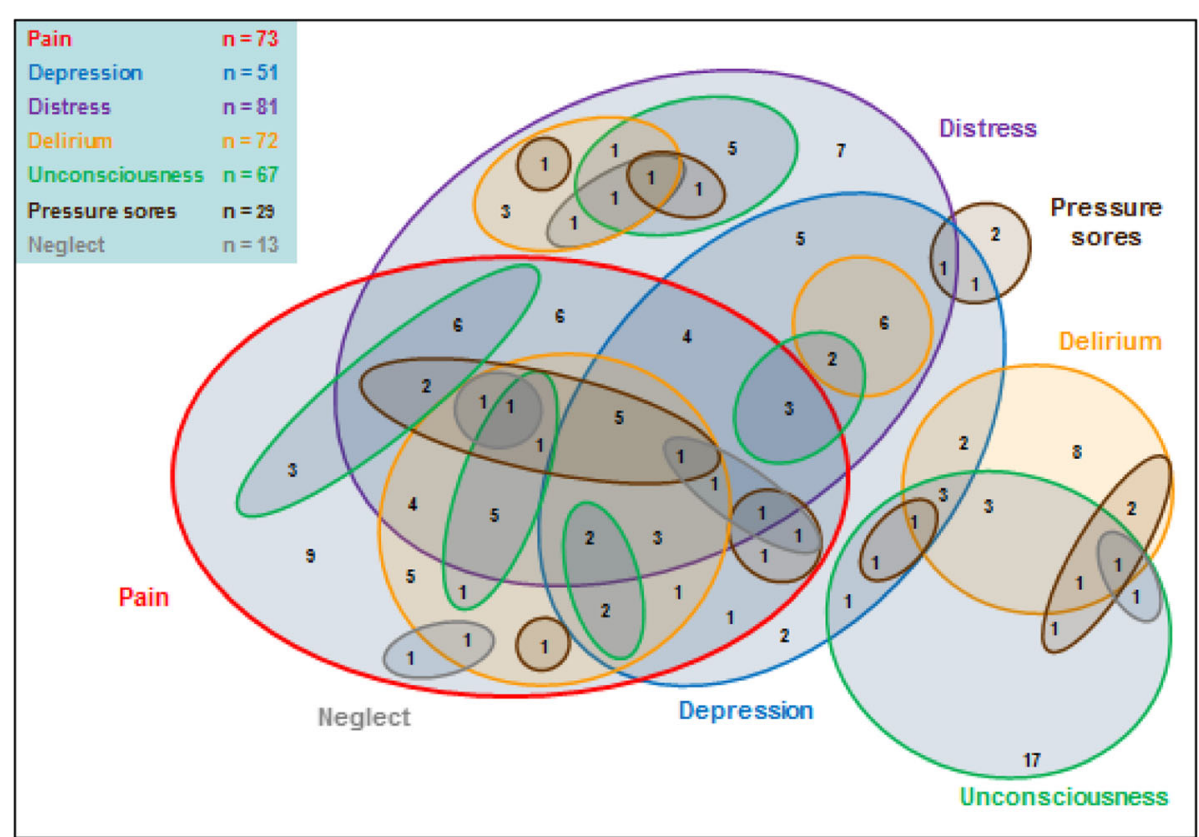

Fig. 3 Distribution of symptoms in the final illness Informants' reports describe a complex overlap of multiple symptoms experienced by very old people in their final illness. Illustrates this for participants with any reported symptoms ( $n=155$ with for whom informants replied "Yes" for at least one symptom; $n=18$ with only "No" responses and $n=7$ with only "No" or "Don't know" responses not shown). The majority (61\%) of participants were reported to have suffered from at least two of the seven symptoms that the study interviews asked about. For only $10 \%$ were none of these symptoms reported, and for a further $4 \%$ informants were unsure whether they had suffered any of these symptoms

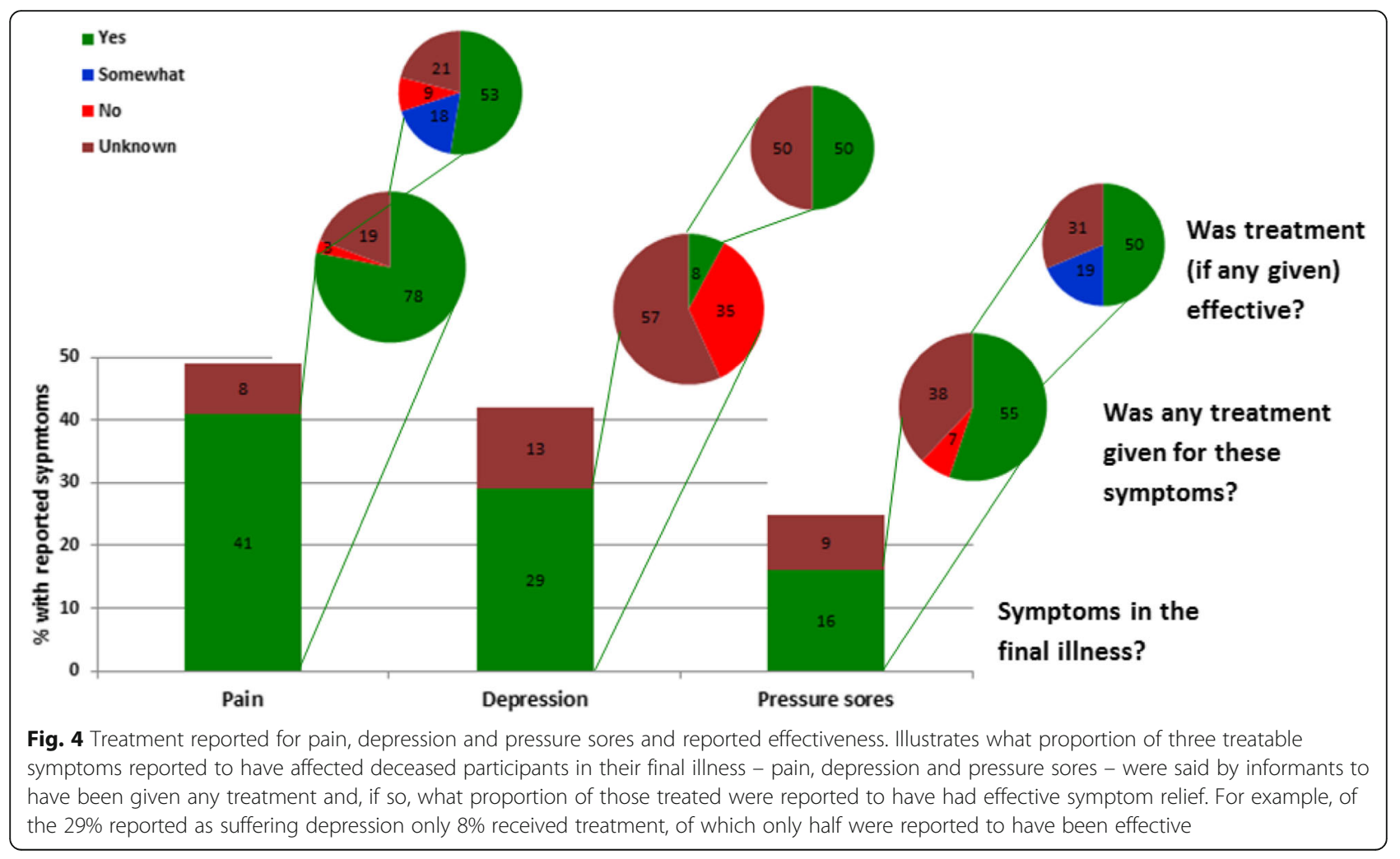


Table 3 Factors potentially related to reported comfort during the final illness

\begin{tabular}{|c|c|c|}
\hline & n "comfortable"/ total each group (\%) & Unadjusted OR (95\% C.I.) \\
\hline \multicolumn{3}{|l|}{ SOCIO-DEMOGRAPHICS } \\
\hline Age & $145 / 180$ & \\
\hline$<90$ years old & $62 / 78(79)$ & 1 \\
\hline$\geq 90$ years old & $83 / 102(81)$ & $1.1(0.5-2.4)$ \\
\hline Sex & $145 / 180$ & \\
\hline Male & $46 / 57(81)$ & 1 \\
\hline Female & 99/123 (80) & $1.0(0.4-2.2)$ \\
\hline Marital status ${ }^{a}$ & $143 / 178$ & \\
\hline Married & $31 / 38(82)$ & 1 \\
\hline Widowed & $98 / 123(80)$ & $0.9(0.3-2.2)$ \\
\hline Single & $14 / 17(82)$ & $1.1(0.2-4.7)$ \\
\hline School leaving age ${ }^{a}$ & $144 / 179$ & \\
\hline$\leq 14$ years old & $90 / 115(78)$ & 1 \\
\hline$\geq 15$ years old & $54 / 64(84)$ & $1.5(0.7-3.4)$ \\
\hline Social class ${ }^{\mathrm{ab}}$ & $143 / 178$ & \\
\hline Non-manual & $61 / 79(77)$ & 1 \\
\hline Manual & $82 / 99$ (83) & $1.4(0.7-3.0)$ \\
\hline Place of residence at last interview ${ }^{c}$ & $145 / 180$ & \\
\hline Home & 104/134 (78) & 1 \\
\hline Long-term care & $41 / 46(89)$ & $2.4(0.9-6.5)$ \\
\hline
\end{tabular}

LOCATION OF END OF LIFE CARE

Place of care during final illness ${ }^{c}$

$145 / 180$

Hospital

$55 / 75(73)$

1

Home

24/33 (73)

$1.0(0.4-2.4)$

Long-term care

66/72 (92)

$4.0(1.5-10.7)$

Place of death ${ }^{c}$

$145 / 180$

Hospital

$59 / 85(69)$

1

Home

$17 / 19(89)$

$3.7(0.8-17.4)$

Long-term care

69/76 (91)

$4.3(1.8-10.7)$

Places of care and death - transitions

$137 / 169$ at the end of life $\mathrm{e}^{\text {ad }}$

Care in final illness: hospital

Place of death: hospital

Final illness: home

Place of death: hospital

Final illness: home

Place of death: home

Final illness: long-term care

Place of death: long-term care

$53 / 71(75)$

1

6/13 (46)

$0.3(0.1-1.0)$

$14 / 16(88)$

$2.4(0.5-11.5)$

$64 / 69(93)$

$4.3(1.5-12.5)$

Place of death same as usual address

$145 / 180$

No

$76 / 105$ (72)

1

Yes

$69 / 75(92)$

$4.4(1.7-11.2)$

HEALTH \& DISABLLTYY

Dementia status

$145 / 180$

No dementia-cognitively intact

25/33 (76)

1

Cognitively impaired +/- minimal/mild dem

$61 / 81(75)$

$1.0(0.4-2.5)$

Moderate/severe dementia

$59 / 66(89)$

$2.7(0.9-8.2)$

Duration of final illness ${ }^{a}$

$145 / 180$

\footnotetext{
Less than a week

7 days up to a month

1 month or more
}

39/44 (89)

1

62/80 (78)

$0.4(0.2-1.3)$

44/56 (79)

$0.5(0.2-1.5)$ 
Table 3 Factors potentially related to reported comfort during the final illness (Continued)

\begin{tabular}{|c|c|c|}
\hline & n "comfortable"/ total each group (\%) & Unadjusted OR (95\% C.I.) \\
\hline No. of hospital admissions/year since last interview ${ }^{\mathrm{a}}$ & 138/173 & \\
\hline None & 79/98 (81) & 1 \\
\hline One or more & $59 / 75(79)$ & $0.9(0.4-1.9)$ \\
\hline Functional disabilities in ADLs & $145 / 180$ & \\
\hline No basic or instrumental ADL disability & $8 / 10(80)$ & 1 \\
\hline Instrumental ADL disability only & $14 / 20(70)$ & $0.6(0.1-3.6)$ \\
\hline Basic + instrumental ADL disability & $123 / 150(82)$ & $1.1(0.2-5.7)$ \\
\hline Receiving service support (excluding long-term care) ${ }^{a}$ & $100 / 130$ & \\
\hline More than once a week & $33 / 51(65)$ & 1 \\
\hline Once a week & $32 / 38(84)$ & $2.9(1.0-8.3)$ \\
\hline None & $35 / 41(85)$ & $3.2(1.1-9.0)$ \\
\hline \multicolumn{3}{|l|}{ INFORMANTS \& INTERVEWS } \\
\hline Informant's sex & $145 / 180$ & \\
\hline Male & $50 / 57(88)$ & 1 \\
\hline Female & 95/123 (77) & $0.5(0.2-1.2)$ \\
\hline Informant's relationship to participant ${ }^{\mathrm{a}}$ & $143 / 178$ & \\
\hline Husband or wife & 15/18 (83) & 1 \\
\hline Son or daughter & 78/97 (80) & $0.8(0.2-3.1)$ \\
\hline Other relative & $8 / 12(67)$ & $0.4(0.1-2.2)$ \\
\hline Friend & $6 / 8(75)$ & $0.6(0.1-4.5)$ \\
\hline Warden or matron & 13/15 (87) & $1.3(0.2-9.0)$ \\
\hline Other & $23 / 28(82)$ & $0.9(0.2-4.4)$ \\
\hline How often informant saw participant & $145 / 180$ & \\
\hline Lived with participant & $24 / 29(83)$ & 1 \\
\hline Daily & $35 / 45(78)$ & $0.7(0.2-2.4)$ \\
\hline More than once a week & $45 / 55(82)$ & $0.9(0.3-3.1)$ \\
\hline Once a week & 18/22 (82) & $0.9(0.2-4.0)$ \\
\hline Less than once a week & $23 / 29(79)$ & $0.8(0.2-3.0)$ \\
\hline Interval from last survey interview to death & $145 / 180$ & \\
\hline$<$ median & $73 / 90(81)$ & 1 \\
\hline$\geq$ median & $72 / 90(80)$ & $0.9(0.4-1.9)$ \\
\hline Interval from death to informant interview & $145 / 180$ & \\
\hline$<$ median & 70/90 (78) & 1 \\
\hline$\geq$ median & 75/90 (83) & $1.4(0.7-3.0)$ \\
\hline
\end{tabular}

\section{Footnotes}

$\mathrm{OR}=$ Odds Ratio (shown to 1 decimal point)

bold $\mathbf{O R}=$ significant $(p<0.05)$; italic bold $\mathbf{O R}=$ borderline significant $(p=0.5)$

95\% C.I. $=95 \%$ Confidence Interval (shown to 1 decimal point)

$\mathrm{ADL}(\mathrm{s})=$ Activity (or Activities) of Daily Living

${ }^{a}$ Variables in which categories total $<180$ had missing data

${ }^{b}$ Social class categorised following contemporary UK Office of National Statistics grading of occupation reported at baseline interview: Non-manual = I, II or IIla, Man-

$\mathrm{ual}=\mathrm{IIIb}$, IV or V

'Home: community-dwelling in a house, flat, 'granny flat' (part of a relative's home) or sheltered accommodation

Long-term care: in an older people's residential home, nursing home or long-stay ward

${ }^{\mathrm{d}}$ To explore the effects of transitions in place of care at the very end of life, the variable Places of care at the end of life was derived from data on where each individual was cared for during their final illness and where they died. Frequencies in other categories were too small (between 1 and 4 people) to calculate any estimates for other combinations of place of care

End-of-life care in long-term care, avoiding transition between care settings at the end of life and not needing support from formal services were associated with dying comfortably, as reported by informants

individuals whose end-of-life care was at home died elsewhere (12\% in care homes, $39 \%$ in hospitals), and this tended to be most likely for those who had needed more formal service support than less $(79 \%, 25 \%, 36 \%$ for $\geq 2,1,0$ service contacts per week respectively, $p=0.03$ ).

\section{Discussion}

Death not occurring until the tenth decade or later is becoming increasingly common, but dying in advanced old age is still relatively rarely described. This population study provides much-needed 


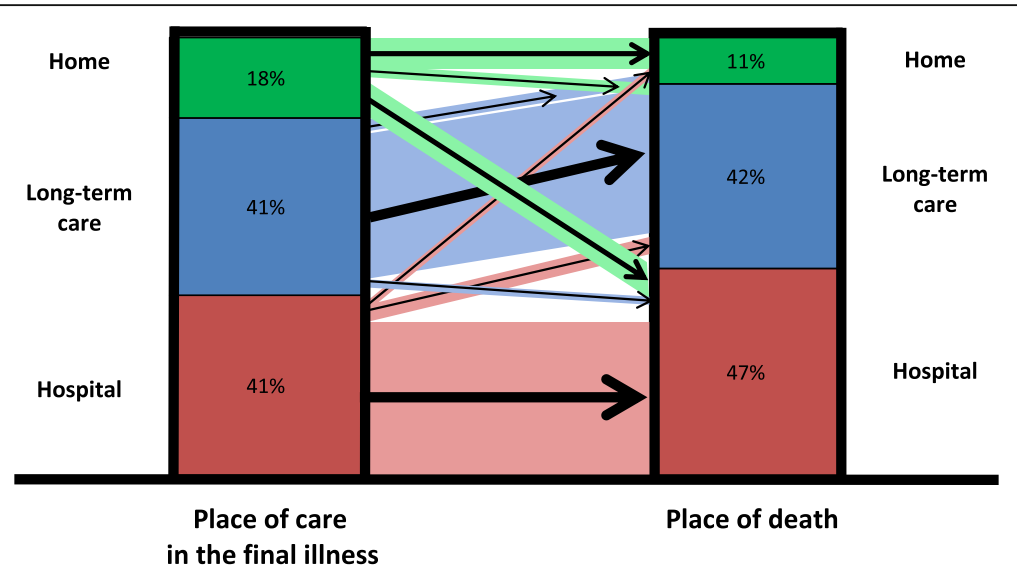

Fig. 5 Transitions between place of care in the final illness and place of death. More than half the individuals whose care during the final illness was at home died elsewhere, whereas the majority of those whose end-of-life care was in hospital or long-term care died there

evidence to inform service planning to support very old people to die comfortably. Nearly half this representative sample of very old people, who died at a median age of 91, experienced at least three symptoms during their final illness. Pain and distress were the most commonly reported, but no clear pattern of symptom clusters emerged. There was some uncertainty about which symptoms were present, particularly depression. Even the largest single symptom group, unconsciousness, was small, suggesting fewer than $10 \%$ of the very old simply 'slip away'. Of the treatable symptoms reported, pain was addressed in the majority affected, though effectively for only half these, but only a fraction of those with depression were treated. Nonetheless, despite high symptom prevalence when dying, death was described as comfortable for the majority. The association found between comfort and effective treatment, nonsignificant within the small sub-sample reported to have had symptoms addressed, may partially explain informants describing many with multiple symptoms as comfortable. Comfort was significantly associated with being cared for in a long term care facility, dying in a long term care facility and also with dying at the individual's usual address. Despite the high proportions of the most cognitively impaired in all these categories, the association between dementia status and reported comfort at the end of life was not significant. Of the majority still living at home when last interviewed, those receiving support more than once a week were more likely to move before they died and less likely to be described as dying comfortably.

A major strength of this study is its combination of prospectively collected data from a representative population-based cohort with retrospective informant interviews and death certificate data, allowing individual- level examination of aspects of end-of-life care experienced by very old people. The CC75C study is one of the very few longstanding population cohorts with participants of such advanced age followed-up to death and data including cognitive assessments from the last year of life. Our sample is sizeable for end-of-life research with very old people, but our focus on deaths in advanced old age inevitably means it is nonetheless too small to fully examine all potentially relevant factors. The hypotheses generated by some of these findings may need testing by combining studies in order to gain sufficient power in future research.

The very nature of such longitudinal research also carries limitations, such as the inevitable absence of more recent measurement approaches [65] and the extended data-collection period. It is possible that experience of death is changing over time, though one study that explored this (in a younger old agerange) found minimal 10-year change in home-tohospital end-of-life transfers and proportions of deaths at home [66]. Information explaining reasons for hospitalisation before death is limited. However, few studies have been able to look at a whole "older old" population and the $\mathrm{CC} 75 \mathrm{C}$ data provide rare insight. Limitations of proxy data from bereaved relatives are well-recognised $[67,68]$ and our informant interview post-bereavement timings varied. Others have explored stability of family informants' responses over time $[69,70]$ and our analyses found no impact on findings of these interval variations. A further limitation with potentially more relevance to our findings is the fact that, although drawn from a representative population-based cohort, our sample inevitably did not include those for whom there was no informant to give a retrospective interview. Assessing potential missing data impacts, we confirmed the analysis sample broadly reflected the full representative cohort. 
Other large population-based studies find prevalences of dementia and cognitive impairment at the end of life at advanced age in line with this study, though most reporting advanced age prevalence [71-74] are not specifically from populations near death [2, 4]. As expected, we found higher disability levels than reported from other "older old" but not end-of-life cohorts $[75,76]$ and from studies of older people nearing death but including a younger old age range [77, 78]. Other population-wide research provides broadly similar figures for the proportion of those dying in different settings, with general concordance that those with no cognitive impairment were most likely to live at home and then move to hospital whereas those with moderate-severe dementia were most likely to live and die in a care home $[39,44,47,66,79]$. Other UK research confirms transitions to hospital before death are usually from home and least likely from nursing homes $[33,43]$.

We found higher comfort ratings in long-term care; the large UK VOICES study also found that care homes and hospices were rated better than home for non-cancer deaths, [7] and the Swedish NONA study found similar satisfaction with care amongst relatives of over-90-yearolds dying in care homes [80]. We recognise that an informant's report of a comfortable death is a subjective measure that may be coloured by many factors and reported comfort in care homes may reflect family hopes or even staff defensiveness, but these conjectures are beyond what the data can elucidate. The non-significant association of moderate-severe dementia with reported comfort is somewhat supported by the VOICES study which found that relatives of people who died with dementia tended to rate the overall level of care better than ratings for those dying without dementia, though they were less likely to rate care excellent. [7] Authors of another study which found it paradoxical that end-of-life care was improved when the person had dementia hypothesised this was possibly due to increased attention levels [81].

The symptom burden is also similar to that found in other research, with pain and distress being common symptoms found in hospitals, care homes and at home in other studies [82-86], and inadequate symptom relief also reported as common [86]. There is discordance in the literature about the impact of symptoms on quality of dying with some finding their presence has no effect [84]; we also found no significant association between symptom presence and comfort.

It is heartening that these very old people, including those with dementia, were described as being comfortable at the end of life. However, the high symptom prevalence, some reportedly inadequately addressed, reinforces calls to improve end-of-life care from a plethora of recent reports [87-89]. That symptoms were common is relevant to current attention to the design and delivery of palliative care [90, 91], particularly the low proportion of depression treated. Mental health at the end of life for the very old needs to be assessed and addressed, likewise the adequacy of pain relief offered, especially considering the inter-play of dementia, depression and distress.

It is important to note the strong inter-relationship of many variables we considered. People with high support needs at home are least likely to 'stay in place'. People with dementia at advanced ages are more likely to live in care homes and experience fewer end-of-life transitions to other settings. From a policy perspective the finding that long-term care settings are associated with dying comfortably supports recent evidence that is starting to encourage re-thinking the focus on dying at home $[20,22,25,26,30,92]$, particularly for this very old age group. Cost-savings arguments based on cancer care service models may be inappropriate to the very different palliative care context for frail older people [53, 55, 93], who cannot always be adequately supported at home [94-97]. There is growing recognition that good care homes increasingly play a role akin to hospices for the frail elderly [98, 99], but common public perceptions [100] tend more to reflect concerns over the wide variability in standards and the challenges many homes face in providing end-of-life care [101-104]. Recent research confirms this is no less a challenge at home $[33,48,51,105-110]$, the setting where the fewest very old people die, though our findings suggest home can be a comfortable place of death provided circumstances support staying there. However, the number of older old people dying in acute hospitals, where we found the odds of dying comfortably were lowest, makes this another priority area for improving end-of-life care [111-119].

Informants sometimes found it difficult to say when the "final illness" began, even in retrospect: this is not unexpected, given many participants' health had been fragile long before death [120]. In all settings, recognising at what point along a frailty trajectory someone is dying is a challenge $[49,80,104,121-123]$ that sometimes hinders advance care planning (ACP). Older people and their families' choices need to be fully informed through realistic discussion anticipating deterioration, something many, but not all, very old people would welcome [105, 124-127]. Early and more widespread discussion of place of care and death, using clear language and frank information could be helpful in reducing the discomfort in talking about death, alleviating some distress and opening communication channels for better symptom control. Transfer to a preferred place of care should be facilitated whenever possible, but all too commonly a patient is admitted to hospital without those concerned having considered where they can be best cared for, or would wish to die. If social/ 
community care use is predictive of end-of-life comfort, as found in our study, this has implications that can guide planning future management of considerable care needs. However, although ACP may reduce unwanted transitions, including hospital admissions [17, 128], even well-informed choices discussed in advance are no guarantee when services cannot cope with changed circumstances [129]. This very unpredictability underlies some reluctance to make plans $[105,124,127]$ and poses big questions for future research and practice: how care for the very old and frail at the end of their lives can be responsive to their preference and deliver the best possible support in all settings for dying comfortably [130].

\section{Conclusions}

This study's findings are consistent with reports that care homes can provide care akin to hospice for the very old and support an approach of supporting residents to stay in their care home or own home if possible. The reported high prevalence of multiple symptoms, but less frequently reported symptom control, can inform policy and training to improve older old people's end-of-life care in all settings.

\section{Additional files}

Additional file 1: Table S1. Factors potentially related to comfort during the final illness. Factors found in univariate logistic regression analyses to be significantly associated with reported comfort during the final illness related to the place of end-of-life care and death, to transitions between these and, for those living at home when last interviewed, to the level of support received from services. As many variables of interest were clearly inter-related, Table S1 shows the effects of adjusting for key significant variables separately on odds ratios associated with all factors potentially related to reported comfort (The 'transitions at the end of life' variable is derived from 'place of care in the final illness' and 'place of death'). Sample size limitations precluded full stepwise multivariable regression modelling. Cognition was hypothesised a priori to be important so, although univariate analyses did not find this a significant factor, ORs adjusted for dementia/ cognitive status are also shown: this adjustment slightly reduced effect sizes but did not remove significance of any associated factors. (DOC $131 \mathrm{~kb}$ )

Additional file 2: Table S2. Factors potentially related to comfort during the final illness - odds ratios adjusted for interview time intervals. Adjusting for the time interval between last study interviews and participants' deaths, and between participants' deaths and retrospective informant interviews after death, made minimal or no difference to associations between reported comfort in the final illness and other potentially related factors. (DOC $125 \mathrm{~kb}$ )

\section{Abbreviations \\ CAMDEX: Cambridge Mental Disorders of the Elderly Examination; CC75C: Cambridge City over-75s Cohort; Cl: Confidence Interval; DSM- IV: Diagnostic and Statistical Manual of Mental Disorders version 4; GP: General practitioner; MMSE: Mini Mental State Examination; OR: Odds Ratio; UK: United Kingdom; VOICES: Views of Informal Carers - Evaluation of Services}

\section{Acknowledgements}

The authors wish to thank particularly the Cambridge City over-75 s Cohort study respondents, their families, friends and the staff in many care homes and collaborating general practices without whose help none of this research would be possible. Many thanks also to our additional interviewers Sarah Shippey and Jenny Sparrow. The current research team gratefully acknowledge the contributions of previous investigators, past research team members and the helpful comments on drafts of this paper from current collaborators (see full list on CC75C study website http://www.cc75c.group.cam.ac.uk/contacts/study-personnel/).

\section{Funding}

We thank all the past CC75C sponsors for financial support spanning the decades since the Medical Research Council enabled the first follow-up survey (see study website for full list of project grants: http://www.cc75c. group.cam.ac.uk/background/grants/). A BUPA Foundation Health and Care of Older People grant supported data collection for these analyses and we particularly thank our current funder Abbeyfield Research Foundation. CC75C was a member study of the National Institute for Health Research funded Collaboration for Leadership in Applied Health Research \& Care (CLAHRC) for Cambridgeshire and Peterborough. No funder sponsor played any role in the study design; in the collection, analysis, and interpretation of data; or in the writing of the report and the decision to submit the article for publication. All researchers were independent from funders.

\section{Availability of data and materials}

The anonymised datasets analysed during the current study are available from the corresponding author on reasonable request through the CC75C study data sharing request procedures.

\section{Authors' contributions}

$J F, C B, S B$ and MF devised the study and obtained funding. JF collected data with acknowledged co-fieldworkers above. AP and JF cleaned and coded the data, conducted the analyses and together wrote the first draft. RC conducted literature reviews and wrote further sections of the draft. CB, MF and SB have contributed to conceptual discussions throughout the research process and to re-drafting the manuscript. JF prepared the final manuscript, read and approved by all authors. JF is the guarantor for the paper.

\section{Ethics approval and consent to participate}

Each CC75C study phase was approved by Cambridge Research Ethics Committee (relevant reference numbers: 06_Q0108_87 and 08_H0308_3) and participants' and proxy informants' consent was re-sought at each new survey and for the informant interviews after participants had died. Consent was obtained from the next of kin for interviews or assessments with any participant with dementia.

\section{Consent for publication}

Not applicable: the manuscript contains no individual person's identifiable data.

\section{Competing interests}

The authors declare that they have no competing interests.

\section{Publisher's Note}

Springer Nature remains neutral with regard to jurisdictional claims in published maps and institutional affiliations.

\section{Author details \\ ${ }^{1}$ Cambridge Institute of Public Health, University of Cambridge, Forvie Site, Robinson Way, Cambridge CB2 OSR, UK. ²Department of Public Health \& Primary Cambridge, University of Cambridge, Cambridge, UK. ${ }^{3}$ North East Thames Foundation School, London, UK. ${ }^{4}$ Faculty of Medicine, Vrije Universiteit, Amsterdam, Netherlands. ${ }^{5}$ School of Health Sciences, University of East Anglia, Norwich, UK. ${ }^{6}$ Primary Care Unit, Department of Public Health \& Primary Cambridge, University of Cambridge, Cambridge, UK}

Received: 8 November 2016 Accepted: 1 September 2017 Published online: 05 October 2017

\section{References}

1. Christensen K, Doblhammer G, Rau R, Vaupel J. Ageing populations: the challenges ahead. Lancet. 2009;374:1196-208.

2. Zhao J, Barclay S, Farquhar M, Kinmonth AL, Brayne C, Fleming J, et al. The "oldest old" in the last year of life: population-based findings from CC75C 
study participants aged at least 85 at death. J Am Geriatr Soc 2010;58(1):1-11.

3. Office For National Statistics. Estimates Of The Very Old (Including Centenarians) For England And Wales, United Kingdom, 2002 To 2013. 25-9-2014. London: Office for National Statistics.

4. Brayne C, Gao L, Dewey M, Matthews FE. Dementia before death in ageing societies- the promise of prevention and the reality. PLoS Med. 2006;3(10):E397.

5. Hendriks SA, Smalbrugge M, Hertogh CM, Van Der Steen JT. Dying with dementia: symptoms, treatment, and quality of life in the last week of life. J Pain Symptom Manag. 2014;47:710-20.

6. Lloyd-Williams M. An audit of palliative care in dementia. Eur J Cancer Care (Engl ). 1996;5:53-5.

7. Hunt KJ, Shlomo N, Addington-Hall J. End-of-life care and achieving preferences for place of death in England: results of a population-based survey using the Voices-Sf questionnaire. Palliat Med. 2014;28(5):412-21. (E-Pub 28/11/2013)

8. Hunt KJ, Shlomo N, Addington-Hall J. End-of-life care and preferences for place of death among the oldest old: results of a population-based survey using Voices-short form. J Palliat Med. 2014;17:176-82.

9. Hales S, Zimmermann C, Rodin G. Review: the quality of dying and death: a systematic review of measures. Palliat Med. 2010;24:127-44.

10. Dy SM, Shugarman LR, Lorenz KA, Mularski RA, Lynn J. A systematic review of satisfaction with care at the end of life. J Am Geriatr Soc. 2008:56:124-9.

11. Aspinal F, Hughes R, Dunckley M, Addington-Hall J. What is important to measure in the last months and weeks of life?: a modified nominal group study. Int J Nurs Stud. 2006;43:393-403.

12. Kehl KA. Moving toward peace: an analysis of the concept of a good death. Am J Hosp Palliat Care. 2006;23:277-86.

13. Steinhauser KE, Christakis NA, Clipp EC, Mcneilly M, Mcintyre L, Tulsky JA. Factors considered important at the end of life by patients, family, physicians, and other care providers. JAMA. 2000;284:2476-82.

14. Heyland DK, Dodek P, Rocker G, Groll D, Gafni A, Pichora D, et al. What matters most in end-of-life care: perceptions of seriously ill patients and their family members. Cmaj: Canadian Medical Association Journal. 2006;174:627-33.

15. Stewart AL, Teno J, Patrick DL, Lynn J. The concept of quality of life of dying persons in the context of health care. J Pain Symptom Manag. 1999;17:93-108.

16. Meier EA, Gallegos JV, Thomas LPM, Depp CA, Irwin SA, Jeste DV. Defining A Good Death (Successful Dying): Literature Review And A Call For Research And Public Dialogue. Am J Geriatr Psychiatry. 2016:24:261-71.

17. Bischoff KE, Sudore R, Miao Y, Boscardin WJ, Smith AK. Advance care planning and the quality of end-of-life care in older adults. J Am Geriatr Soc. 2013;61:209-14.

18. Gomes B, Higginson IJ, Calanzani N, Cohen J, Deliens L, Daveson BA, et al. Preferences for place of death if faced with advanced cancer: a population survey in England, Flanders, Germany, Italy, The Netherlands, Portugal and Spain. Ann Oncol. 2012;23:2006-15.

19. Wilson DM, Cohen J, Deliens L, Hewitt JA, Houttekier D. The preferred place of last days: results of a representative population-based public survey. J Palliat Med. 2013;16:502-8.

20. Gomes B, Calanzani N, Gysels M, Hall S, Higginson I. Heterogeneity and changes in preferences for dying at home: a systematic review. Bmc Palliative Care. 2013;12:7.

21. Office For National Statistics. National Bereavement Survey (Voices), 2011. 3-7-2012. London.

22. Hoare S, Morris ZM, Kelly MP, Kuhn I, Barclay S. Do patients want to die at home? A systematic review of the UK literature, focused on missing preferences for place of death. PLOS ONE. 2015. https://doi.org/10.1371/ journal.pone.0142723.

23. Evans R, Finucane A, Vanhegan L, Arnold E, Oxenham D. Do place-of-death preferences for patients receiving specialist palliative care change over time? Int J Palliat Nurs. 2014;20:579-83.

24. Aoun SM, Skett K. A longitudinal study of end-of-life preferences of terminally-ill people who live alone. Health Soc Care Community. 2013;21:530-5

25. Wilson DM. End-of-life care preferences of Canadian senior citizens with Caregiving experience. J Adv Nurs. 2000;31:1416-21.

26. Gott M, Seymour J, Bellamy G, Clark D, Ahmedzai S. Older People's views about home as a place of care at the end of life. Palliat Med. 2004;18:460-7.

27. Department Of Health. End of life care strategy: promoting high quality care for all adults at the end of life. London: Dh; 2008.
28. Department Of Health. End of life care strategy: fourth annual report. 2012.

29. Department Of Health. End of life care strategy: quality markers and measures for end of life care. 2009.

30. Pollock K. Is home always the best and preferred place of death? BMJ. 2015 Oct 7;351:H4855.

31. Fleming J, Zhao J, Farquhar M, Brayne C, Barclay S. Place of death for the 'oldest old': >=85-year-olds in the CC75C population-based cohort. Br J Gen Pract. 2010;60:171-9.

32. Perrels AJ, Fleming J, Zhao J, Barclay S, Farquhar M, Buiting HM, et al. Place of death and end-of-life transitions experienced by very old people with differing cognitive status: retrospective analysis of a prospective populationbased cohort aged 85 and over. Palliat Med. 2014;28:220-33.

33. Evans CJ, Bone A, Morgan M, Mccrone P, Gaoi W, Wright J, et al. Optimising palliative care for frail elders in community settings: preferences for care and palliative outcomes in the last months of life. BMJ Support Palliat Care. 2014:4:111-2.

34. Fried TR, Van DC, O'leary JR, Tinetti ME, Drickamer MA. Older persons' preferences for site of terminal care. Ann Intern Med. 1999;131:109-12.

35. Sleeman KE, Davies JM, Verne J, Gao W, Higginson IJ. The changing demographics of inpatient hospice death: population-based crosssectional study in England, 1993-2012. Palliat Med. 2016;30(1):45-53. (EPub 19/05/2015)

36. Grande GE, Addington-Hall JM, Todd CJ. Place of death and access to home care services: are certain patient groups at a disadvantage? Soc Sci Med. 1998:47:565-79.

37. Grande GE, Farquhar MC, Barclay SI, Todd CJ. The influence of patient and Carer age in access to palliative care services. Age Ageing. 2006;35:267-73.

38. Buck J, Moth L, Morgan L, Webb L, Barclay S. Inequities in a service struggling to meet demand: findings from an evaluation of a hospice at home service in Cambridgeshire. Palliat Med. 2016;30(4):S54.

39. Sleeman KE, Ho YK, Verne J, Gao W, Higginson IJ, Guide C. Reversal of English trend towards hospital death in dementia: a population-based study of place of death and associated individual and regional factors, 2001-2010. BMC Neurol. 2014;14:59.

40. Li Q, Zheng N, Temkin-Greener H. Quality of end-of-life care of long-term nursing home residents with and without dementia. J Am Geriatr Soc. 2013; 61:1066-73

41. Vandervoort A, Van Den Block L, Van Der Steen J, Volicer L, Vander SR, Houttekier D, et al. Nursing home residents dying with dementia in Flanders, Belgium: a Nationwide postmortem study on clinical characteristics and quality of dying. J Am Med Dir Assoc. 2013;14:485-92.

42. Aaltonen M, Raitanen J, Forma L, Pulkki J, Rissanen P, Jylhä M. Burdensome transitions at the end of life among long-term care residents with dementia. J Am Med Dir Assoc. 2014;15:643-8.

43. Evans CJ, Bone AE, Yi D, Wei G, Gomes B, Maddocks M, et al. Factors associated with end of life transition for older adults living at home: analysis of Carers' post-bereavement survey. BMJ Support Palliat Care. 2015;5:116.

44. Mitchell SL, Teno JM, Miller SC, Mor V. A national study of the location of death for older persons with dementia. J Am Geriatr Soc. 2005;53:299-305.

45. Badrakalimuthu V, Barclay S. Do people with dementia die at their preferred location of death? A systematic literature review and narrative synthesis. Age Ageing. 2014;43:13-9.

46. Murtagh F, Bausewein C, Petkova H, Sleeman K, Dodd R, Gysels M Et Al.. Understanding place of death for patients with non malignant conditions: a systematic literature review. Final report. 2012. Nihr Service Delivery And Organisation Programme.

47. Klinkenberg M, Visser G, Van Groenou MI, Van Der Wal G, Deeg DJ, Willems $\mathrm{DL}$. The last 3 months of life: care, transitions and the place of death of older people. Health Soc Care Community. 2005;13:420-30.

48. Lakasing E, Kulkarni S, Sparkes C, Ravichander R. A practice-based survey of patients dying in hospital: can we do more to support end-of-life care at home? British Journal Of Community Nursing. 2014;19:130-3.

49. Barclay S, Froggatt K, Crang C, Mathie E, Handley M, Iliffe S, et al. Living in uncertain times: trajectories to death in residential care homes. $\mathrm{Br} J \mathrm{Gen}$ Pract. 2014;64:E576-83

50. Hanratty B, Lowson E, Grande G, Payne S, Addington-Hall J, Valtorta N, et al. Transitions At The End Of Life For Older Adults - Patient, Carer And Professional Perspectives: A Mixed-Methods Study. Health Serv Deliv Res 2014, No. 2.17.

51. Hanratty B, Holmes L, Lowson E, Grande G, Addington-Hall J, Payne S, et al. Older adults' experiences of transitions between care settings at the end of 
life in England: a qualitative interview study. J Pain Symptom Manag. 2012:44:74-83.

52. Boockvar K, Fishman E, Kyriacou CK, Monias A, Gavi S, Cortes T. Adverse events due to discontinuations in drug use and dose changes in patients transferred between acute and long-term care facilities. Arch Intern Med. 2004;164:545-50.

53. Hatziandreu E, Archontakis F, Daly A. The potential cost savings of greater use of home and hospice based end of life care in England. London: National Audit Office; 2008

54. Gardiner C, Ward S, Gott M, Ingleton C. Economic impact of Hospitalisations among patients in the last year of life: an observational study. Palliat Med. 2013;28:422-9.

55. Georghiou T, Bardsley M. Exploring the costs of care at the end of life. London: Nuffield Trust; 2014. p. 1-31.

56. Goldfeld KS, Hamel MB, Mitchell SL. The cost-effectiveness of the decision to hospitalize nursing home residents with advanced dementia. J Pain Symptom Manag. 2013;46:640-51.

57. Fleming J, Zhao E, O'connor Dw, Pollitt Pa, Brayne C, CC75C Study Collaboration: Cohort Profile: The Cambridge City Over-75s Cohort (CC75C). Int J Epidemiol 2007, 36: 40-46.

58. Cambridge City Over-75s Cohort (CC75C) Study Website. University Of Cambridge. 2016. http://www.cc75c.group.cam.ac.uk/.

59. Folstein MF, Folstein SE, Mchugh PR. "Mini-mental state". A practical method for grading the cognitive state of patients for the clinician. J Psychiatr Res. 1975;12:189-98

60. Roth M, Tym E, Mountjoy CQ, Huppert FA, Hendrie H, Verma S, et al. Camdex. A standardised instrument for the diagnosis of mental disorder in the elderly with special reference to the early detection of dementia. $\mathrm{Br} J$ Psychiatry. 1986;149:698-709.

61. American Psychiatric Association. Diagnostic and statistical manual of mental disorders. 4th Edition, Revised ed; 2000

62. Brayne C, Richardson K, Matthews FE, Fleming J, Hunter S, Xuereb J, et al. Neuropathological correlates of dementia in Over-80-year-old brain donors from the population-based Cambridge City over-75s cohort (CC75C) study. J Alzheimers Dis. 2009;18(3):645-58.

63. Cambridge City Over-75s Cohort (CC75C) Study Documentation - Links To All Questionnaires. University Of Cambridge. 2016. http://www.cc75c.group. cam.ac.uk/documentation/questionnaires/.

64. James Lind Alliance. Palliative and end of life care priority setting partnership (Peolcpsp): putting patients, Carers and clinicians at the heart of palliative and end of life care research. 1-28. 2015. London, James Lind Alliance.

65. Evans CJ, Benalia H, Preston NJ, Grande G, Gysels M, Short V, et al. The selection and use of outcome measures in palliative and end-of-life care research: the Morecare international consensus workshop. J Pain Symptom Manag. 2013;46:925-37.

66. Kaspers PJ, Pasman H, Onwuteaka-Philipsen BD, Deeg DJ. Changes over a decade in end-of-life care and transfers during the last 3 months of life: a repeated survey among proxies of deceased older people. Palliat Med. 2013;27:544-52.

67. Higginson I, Priest P, Mccarthy M. Are bereaved family members a valid proxy for a Patient's assessment of dying? Soc Sci Med. 1994;38:553-7.

68. Mcpherson CJ, Addington-Hall J. Judging the quality of care at the end of life: can proxies provide reliable information? Soc Sci Med. 2003;56:95-109.

69. Mcpherson CJ, Addington-Hall JM. How do proxies' perceptions of patients' pain, anxiety, and depression change during the bereavement period? J Palliat Care. 2004;20(1):12-9.

70. Dibiasio EL, Clark MA, Gozalo PL, Spence C, Casarett DJ, Teno JM. Timing of survey administration after hospice patient death: stability of bereaved respondents. J Pain Symptom Manag. 2015;50:17-27.

71. Qiu C, Von Strauss E, Backman L, Winblad B, Fratiglioni L. Twenty-year changes in dementia occurrence suggest decreasing incidence in Central Stockholm, Sweden. Neurology. 2013;80:1888-94.

72. Christensen K, Thinggaard M, Oksuzyan A, Steenstrup T, AndersenRanberg K, Jeune B, et al. Physical and cognitive functioning of people older than 90 years: a comparison of two Danish cohorts born 10 years apart. Lancet. 2013;382:1507-13.

73. Matthews FE, Arthur A, Barnes LE, Bond J, Jagger C, Robinson L, et al. A two-decade comparison of prevalence of dementia in individuals aged 65 years and older from three geographical areas of England: results of the cognitive function and ageing study I and ii. Lancet. 2013;382:1405-12.

74. Rocca WA, Petersen RC, Knopman DS, Hebert LE, Evans DA, Hall KS, et al. Trends in the incidence and prevalence of Alzheimer's disease, dementia, and cognitive impairment in the United States. Alzheimer's \& Dementia: The Journal Of The Alzheimer's Association. 2011;7:80-93.

75. Nybo H, Gaist D, Jeune B, Mcgue M, Vaupel JW, Christensen K. Functional status and self-rated health in 2,262 nonagenarians: the Danish 1905 cohort survey. J Am Geriatr Soc. 2001;49:601-9.

76. Bootsma-Van Der Wiel A, Gussekloo J, De Craen AJ, Van Exel E, Knook D, Lagaay A, et al. Disability in the oldest old: "can do" or "do do". J Am Geriatr Soc. 2001:49:909-14

77. Smith AK, Walter LC, Miao Y, Boscardin W, Covinsky KE. Disability during the last two years of life. JAMA Intern Med. 2013;173:1506-13.

78. Covinsky KE, Eng C, Lui LY, Sands LP, Yaffe K. The last 2 years of life: functional trajectories of frail older people. J Am Geriatr Soc. 2003;51:492-8.

79. Houttekier D, Cohen J, Bilsen J, Addington-Hall J, Onwuteaka-Philipsen BD, Deliens $L$. Place of death of older persons with dementia. A study in five European countries. J Am Geriatr Soc. 2010;58:751-6.

80. Bravell ME, Malmberg B, Berg S: End-Of-Life Care In The Oldest Old. Palliative \& Supportive Care 2010, 8: 335-344.

81. Caprio AJ, Hanson LC, Munn JC, Williams CS, Dobbs D, Sloane PD, et al. Pain, Dyspnea, and the quality of dying in long-term care. J Am Geriatr Soc. 2008;56:683-8.

82. Ryan T, Ingleton C, Gardiner C, Parker C, Gott M, Noble B. Symptom burden, palliative care need and predictors of physical and psychological discomfort in two Uk hospitals. Bmc Palliat Care. 2013;12:11.

83. Lukas A, Mayer B, Fialova D, Topinkova E, Gindin J, Onder G, et al. Pain characteristics and pain control in European nursing homes: cross-sectional and longitudinal results from the services and health for elderly in long term care (shelter) study. J Am Med Dir Assoc. 2013;14:421-8.

84. Kutner JS, Bryant LL, Beaty BL, Fairclough DL. Time course and characteristics of symptom distress and quality of life at the end of life. J Pain Symptom Manag. 2007:34:227-36.

85. Mccarthy M, Addington-Hall J, Altmann D. The experience of dying with dementia: a retrospective study. Int J Geriatr Psychiatry. 1997;12:404-9.

86. Burt J, Shipman C, Richardson A, Ream E, Addington-Hall J. The experiences of older adults in the community dying from cancer and non-cancer causes: a National Survey of Bereaved Relatives. Age Ageing. 2010;39:86-91.

87. Leadership Alliance For The Care Of Dying People. One chance to get it right: improving People's experience of care in the last few days and hours of life. 2014. 24-1-2016.

88. House Of Commons Health Committee. End of life care: fifth report of session 2014-2015. 15-3-2015. London, The Stationery Office Limited. 24-1-2016.

89. Parliamentary And Health Service Ombudsman. Dying Without Dignity. 1-30. 20-5-2015. London.

90. World Health Organisation. Palliative care for older people - better practices. 2011. 24-1-2016.

91. Kinley J, Stone L, Hockley J: St Christopher's Hospice Clinical Guidelines: Anticipatory End-Of-Life Care Medication For The Symptoms Of Terminal Restlessness, Pain And Excessive Secretions In Frail Older People In Care Homes. End Of Life J 2013, 3.

92. Higginson IJ, Sarmento VP, Calanzani N, Benalia H, Gomes B. Dying at home-is it better: a narrative appraisal of the state of the science. Palliat Med. 2013;27:918-24.

93. Dixon J, King D, Matosevic T, Clark M, Knapp M. Equity in the provision of palliative care in the Uk: review of evidence. 2015. 24-1-2016.

94. Connolly J, Milligan SD: Knowledge And Skills Needed By Informal Carers To Look After Terminally III Patients At Home. End Of Life Journal 2014, 4.

95. Watson $\mathrm{H}$. Challenges of domiciliary Carers when providing end-of-life care. End Of Life Journal. 2011;

96. National Palliative And End Of Life Care Partnership. Ambitions for palliative and end of life care: a National Framework for Local Action 2015-2020, 2015. London: National Palliative And End Of Life Care Partnership.

97. The Choice In End Of Life Care Programme Board. What's Important To Me. A Review Of Choice In End Of Life Care. 2015. London. 24-1-2016.

98. Teno JM. Now is the time to embrace nursing homes as a place of care for dying persons. J Palliat Med. 2003:6:293-6.

99. Towsley GL, Hirschman KB, Madden C. Conversations about end of life: perspectives of nursing home residents, family And Staff. J Palliat Med. 2015;18(5):421-8.

100. Calanzani N, Moens K, Cohen J, Higginson I, Harding R, Deliens L, et al. Choosing care homes as the least preferred place to die: a cross-National Survey of Public Preferences in Seven European Countries. Bmc Palliative Care. 2014;13:48 
101. Seymour JE, Kumar A, Froggatt K. Do nursing homes for older people have the support they need to provide end-of-life care? A mixed methods enquiry in England. Palliat Med. 2011;25:125-38.

102. Reitinger E, Froggatt K, Brazil K, Heimerl K, Hockley J, Kunz R, et al. Palliative care in long-term care settings for older people: findings from an Eapc taskforce. Eur J Palliat Care. 2013;20(5):251-3.

103. Kinley J, Hockley J, Stone L, Dewey M, Hansford P, Stewart R, et al. The provision of care for residents dying in Uk nursing care homes. Age Ageing. 2014;43:375-9.

104. Goodman C, Froggatt K, Amador S, Mathie E, Mayrhofer A. End of life care interventions for people with dementia in care homes: addressing uncertainty within a framework for service delivery and evaluation. Bmc Palliat Care. 2015;14:42.

105. Garavan R, Mcgee HM, Winder R, O'neill D. When and how older people discuss preferences for long-term care options. J Am Geriatr Soc. 2009;57:750-1.

106. Goodman C, Evans C, Wilcock J, Froggatt K, Drennan V, Sampson E, et al. End of life care for community dwelling older people with dementia: an integrated review. Int J Geriatr Psychiatry. 2010;25:329-37.

107. Ellins J, Glasby J, Tanner D, Mciver S, Davidson D, Littlechild R Et Al.. Understanding And Improving Transitions Of Older People: A User And Carer Centred Approach - Full Report. 2012. National Institute Of Health Research Health Service And Delivery Research.

108. Hanratty B, Lowson E, Holmes L, Grande G, Addington-Hall J, Payne S, et al. Funding health and social services for older people - a qualitative study of care recipients in the last year of life. J R Soc Med. 2012;105:201-7.

109. Muller-Mundt G, Bleidorn J, Geiger K, Klindtworth K, Pleschberger S,

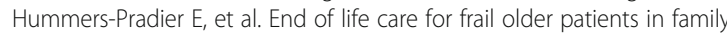
practice (Elfop) - protocol of a longitudinal qualitative study on needs, appropriateness and utilisation of services. BMC Fam Pract. 2013;14:52

110. Ball MM, Kemp CL, Hollingsworth C, Perkins MM. "This is our last stop": negotiating end-of-life transitions in assisted living. J Aging Stud. 2014;30:1-13.

111. Sampson EL, Gould V, Lee D, Blanchard MR. Differences in care received by patients with and without dementia who died during acute hospital admission: a retrospective case note study. Age Ageing. 2006;35:187-9.

112. Abel J, Rich A, Griffin T, Purdy S. End-of-life care in hospital: a descriptive study of all inpatient deaths in 1 year. Palliat Med. 2009;23:616-22.

113. Brereton L, Gardiner C, Gott M, Ingleton C, Barnes S, Carroll C. The hospital environment for end of life care of older adults and their families: an integrative review. J Adv Nurs. 2012;68:981-93.

114. Murphy M, Martikainen P. Use of hospital and long-term institutional care services in relation to proximity to death among older people in Finland. Soc Sci Med. 2013;88:39-47.

115. Robinson J, Gott M, Ingleton C. Patient and family experiences of palliative care in hospital: what do we know? An integrative review. Palliat Med. 2014;28:18-33.

116. Benson D, Mucci E. A future care planning Intiative to improve the end of life care of patients on the complex care Ward of a district general hospital. Future Hospital Journal. 2015;2(2):87-9.

117. Caswell G, Pollock K, Harwood R, Porock D. Communication between family Carers and health professionals about end-of-life care for older people in the acute hospital setting: a qualitative study. Bmc Palliative Care. 2015;14:35.

118. Pollock K, Wilson E. Care and communication between health professionals and patients affected by severe or chronic illness in community care settings: a qualitative study of care at the end of life. Health Services And Delivery Research. 2015;

119. Virdun C, Luckett T. Davidson pm, Phillips J: dying in the hospital setting: a systematic review of quantitative studies identifying the elements of endof-life care that patients and their families rank as being most important. Palliat Med. 2015;29:774-96.

120. Lynn J. Living Long In Fragile Health: The New Demographics Shape End Of Life Care. Hastings Center. Improving End Of Life Care: Why Has It Been So Difficult? Hastings Centre Report Special Report. 2005;35:S14-8.

121. Gibbins J, Mccoubrie R, Alexander V, Kinzel C, Forbes K. Diagnosing dying in the acute hospital setting - are we too late? Clinical Medicine. 2009;9:116-9.

122. Gott M, Ingleton C, Bennett MI, Gardiner C. Transitions to palliative care in acute hospitals in England: qualitative study. BMJ. 2011;342:D1773.

123. Gott M, Ingleton C, Gardiner C, Richards N, Cobb M, Ryan A Et Al:: Transitions to palliative care for older people in acute hospitals: a mixed-methods study. Health Serv Deliv Res 2013, 1.

124. Barclay S, Case-Upton S. Knowing Patients' preferences for place of death: how possible or desirable? Br J Gen Pract. 2009;59:642-3.
125. Barclay S, Momen N, Case-Upton S, Kuhn I, Smith E. End-of-life care conversations with heart failure patients: a systematic literature review and narrative synthesis. Br J Gen Pract. 2011;61:E49-62.

126. Sharp T, Moran E, Kuhn I, Barclay S. Do the elderly have a voice? Advance care planning discussions with frail and older individuals: a systematic literature review and narrative synthesis. Br J Gen Pract. 2013;63:E657-68.

127. Fleming J, Farquhar M. Death and the Oldest Old: Attitudes and Preferences for End-of-Life Care - Qualitative Research within a Population-Based Cohort Study. Cambridge City over-75s Cohort (CC75C) study collaboration. Carol Brayne, Stephen Barclay. PLOS ONE. 2016. https://doi.org/10.1371/journal. pone.0150686

128. Baker A, Leak P, Ritchie LD, Lee AJ, Fielding S. Anticipatory care planning and integration: a primary care pilot study aimed at reducing unplanned hospitalisation. Br J Gen Pract. 2012;62:E113-20.

129. Borgstrom E, Walter T. Choice and compassion at the end of life: a critical analysis of recent English policy discourse. Soc Sci Med. 2015;136gçô137:99-105.

130. Barclay S, Arthur A. Place of death - how much does it matter? The priority is to improve end-of-life care in all settings. Br J Gen Pract. 2008;58:229-31.

\section{Submit your next manuscript to BioMed Central and we will help you at every step:}

- We accept pre-submission inquiries

- Our selector tool helps you to find the most relevant journal

- We provide round the clock customer support

- Convenient online submission

- Thorough peer review

- Inclusion in PubMed and all major indexing services

- Maximum visibility for your research

Submit your manuscript at www.biomedcentral.com/submit
Biomed Central 